\title{
Research and App Design for social problems in the University -with UX research method
}

\author{
Mo Ya Ju1,a, Thure Waleer ${ }^{2, b}$ \\ ${ }^{1}$ Department of Communication, National Chiao Tung University, 300, Taiwan \\ 2 Department of Communication, National Chiao Tung University, 300, Taiwan \\ axyxy588@gmail.com \\ *Mo Ya Ju
}

Keywords: User experience design, App design, User experience, Design method, Social problem

\begin{abstract}
The research focus on how to discover social problems in the university and find a solutions with UX research method and UX design. To collect the data, build personas and find critical social problems, eight students were invited for the interviews. According to the persona, authors started to design the APP prototype for the user. The idea of the design was based on the interview data and "the third place theory". The prototype was used and modified after the task testing. At the final stage for UX design process, usability test was applied to evaluate the APP and degree of user satisfaction.
\end{abstract}

\section{改善校園社交問題之研究與APP設計 \\ --以使用者經驗設計為研究方法 \\ 莫雅如 ${ }^{1, a *}$, Thure Waller ${ }^{2}$ \\ 1國立交通大學傳播研究所, 新竹, 台灣 \\ 2國立交通大學傳播研究所, 新竹, 台灣 \\ axyxy588@gmail.com \\ *莫雅如}

关键词：使用者經驗設計、設計方法、校園社交、APP設計

中文摘要. 研究欲以使用者經驗研究方法, 尋找目標使用者並了解其社交困難點與需求, 設 計出符合其需求與使用經驗的APP。研究從使用者訪談開始, 了解校園使用者的類型, 建立 人物分類 (人物誌)。並挑選適合的對象實際操作雛形，以了解使用者操作困難與改善意見。 根據訪談建議, 進行APP設計更動, 執行任務與易用性測試, 分析其滿足程度, 並在操作後 再次進行訪談, 分析其滿足原因與需要修改之方向。研究發現, 學生大部分都會聚集在同一 交集點亦稱為「第三地點」，能在此地點創造出更多互動的機會，因此針對學生在此的行為 與社交需求，設計出一款可以在交會點尋找相同興趣或參加相同活動的APP。 


\section{1. 動機與目的}

從使用者研究中發現, 大學生校園生活中的社交活動, 大部分都在線上進行, 而實際生活 中, 卻少有機會認識新朋友。但學校中最多的就是各式各樣的活動, 有社團活動、院系活動、 學校舉辦之活動或球隊運動活動，這些活動都是學生可以認識新朋友的機會。受訪的外向使 用者，皆喜歡交朋友，也樂於參加不同的活動，但學校能夠統整活動資訊的平台卻不多，例 如:社團活動與成果發表等活動，宣傳金費有限，也只會在少數地方張貼公告，學生沒有習慣 看公佈欄，但卻天天使用手機上網，學校網站也不會公告此類活動。此外，若學生不是社團 人員, 也很難知道相關活動。外向使用者也提到, 如果要與不同種類或專業的同學聊天，不 知道他 們喜歡什麼, 覺得要有共同的話題, 比較容易建立關係。對於不同興趣的同學, 也希 望能透過參與相關活動, 以瞭解更多。因此, 本研究想要以使用者經驗設計方法, 尋找目標 使用者, 了解其困難點與需求建立一個符合其需求的 $\mathrm{app}$, 以協助同學解決校園社交問題。

\section{2. 使用者經驗研究方法}

根據Nielsen Norman Group所整理之使用者經驗方法（表一），分為四大部分：發覺、探 索、測試與聆聽。其文章也提出三大建議, 第一, 現在就開始做使用者研究, 並將研究結果 應用在產品。第二, 在各個設計階段都要做使用者測試與研究, 透過測試與研究, 從使用者 身上得到很多有用的資訊，能使產品增加的價值會遠高於投資成本。第三，在專案的早期做 使用者研究, 能有較大的影響力, 畢竟到了專案的晚期設計修改不易, 會耗費較多的成本。 而每個階段因不同的產品與階段, 可能使用不同的研究方法。方法的決定也會因為目的的不 同，而有所差異。根據其研究統計，四個階段最常使用的方法為使用者訪談、任務測試分析、 易用性測試與資料分析。

表 1 使用者經驗研究方法整理表

\begin{tabular}{|c|c|}
\hline \multicolumn{2}{|r|}{ Top UX Research Methods } \\
\hline Discover & $\begin{array}{l}\text { - Field study } \\
\text { - Diary study } \\
\text { - User interview } \\
\text { - Stakeholder interview } \\
\text { - Requirements \& constraints gathering }\end{array}$ \\
\hline Explore & $\begin{array}{l}\text { - Competitive analysis } \\
\text { - Design review } \\
\text { - Persona building } \\
\text { - Task analysis } \\
\text { - Journey mapping } \\
\text { - Prototype feedback \& testing (clickable or paper prototypes) } \\
\text { - Write user stories } \\
\text { - Card sorting }\end{array}$ \\
\hline Test & $\begin{array}{l}\text { - Qualitative usability testing (in-person or remote) } \\
\text { - Benchmark testing } \\
\text { - Accessibility evaluation }\end{array}$ \\
\hline Listen & $\begin{array}{l}\text { - Survey } \\
\text { - Analytics review } \\
\text { - Search-log analysis } \\
\text { - Usability-bug review } \\
\text { - Frequently-asked-questions (FAQ) review }\end{array}$ \\
\hline
\end{tabular}

資料來源：Nielsen Norman Group-UX Research Cheat sheet (2017)

\section{3. 研究方法}

本研究運用使用者經驗的開發流程進行問題解決與APP設計。研究試圖使用APP改善校園 問題，因此先從使用者訪談開始，了解校園使用者的類型，建立人物分類（人物誌）。並挑 選適合的對象實際操作雛形，以了解使用者操作困難與改善意見，進行APP設計更動。最後， 
進行任務與易用性測試, 分析其滿足程度, 並在操作後再次進行訪談, 了解滿足原因、提出 修改方向。流程如下圖:



圖 1 研究設計流程圖

\section{4. 訪談資料分析}

\subsection{APP目標使用者}

本研究共訪談八位學生，了解其在校社交狀況與社交困難點，先邀請兩位碩士生、三位 學士生進行訪談, 分類出三種社交類型, 而後又邀請一位碩士生兩位學士生受訪, 確認皆能 被三種類型歸納。分析整理歸納出三種人物誌後, 選擇對象為外向型 outgoing 的使用者, 在 人物誌中的代表人物為 Chris。目前就讀台灣大學資管所, 活潑、積極, 熱愛籃球, 大學為 校隊風雲人物, 平時只要有空就去打球, 認為打球時能創造共同的美好回憶。喜歡吸收新知, 在系上成績 也不錯，也喜歡新奇、酷炫的東西，更想要結交新朋友或不同領 域的人。社交 活動目的, 希望能夠維繫感情與創造共同回憶, 除了球場外, 比較少有機會遇到不同領域的 人與新朋友。動機比較目的性, 對於自己做什麼事情都有一定的要求, 也回追求自我精進, 更喜歡新穎有趣的東西。社交活動上, 籃球團隊活動較多, 主要也與熟識的球友一起活動, 除了社團, 其他社交活動皆在線上進行, 會積極主動去認識新朋友, 但能認為認識新朋友的 機會比較少。

\section{2 使用者目標分析}

而此類使用者的終身長期目標為擁有一個多采多姿、多樣的生活;最終目標為希望能有更 多朋友與參與不同的活動;而經驗目標為感受到好玩、新奇、嶄新與有趣。本研究也針對此類 使用者的目標, 進行創意發想, 期望能符合使用者需求。在 Culture probe 中也發現, 校園中 存在『第三地點』。根據 Ray Oldenburg $(1989,1991)$ 提出, 第一地點為家, 第二地點為工作 場域, 第三地點為社交場域, 如:咖啡廳、酒吧、公園。並指出第三地點對於公民社會、民主、 公民參與是重要的, 也一個可以建立感情的地方。

根據訪談，學生在校園中最常聚集的『第三地點』，也就是大家常走的路線的交集點， 會經過、停留或聚在一起的地方是『公車站牌』。每天都 會有許多學生聚集於此, 經過觀察, 學生都會乘乘排隊等公車, 而等待時間沒有特定目的要做什麼, 大多只是拿出手機看看 FB 與 Line。本研究想要利用此空閒時間, 讓同學與附近同學有所連結、建立關係, 利用 GPS 定 位與 AR 技術, 看到附近同學的喜好或將要發生的活動, 進而拓展交友圈, 更有機會藉由參 與活動，認識相同或不同興趣、專業之學生。

\section{APP設計}

\section{1 初步觹形設計}

主要有兩大功能: 提供聊天的話題與社交活動。以 GPS定位的方式，搜尋附近用戶並顯 示其與使用者的距離，使用者點入有興趣的用戶圖像 後, 可以看到其基本資料, 並會依照用 
戶的興趣顯示推薦話題, 還會顯示 用戶將要參與的活動及其發出的邀請, 可以與之聊天, 或 參加其將要參 與、舉辦的活動。而為了要促進用戶參加活動或在現實社交場合中, 與其 他 用戶互動, 訊息將限制字數 150 個字, 或在五行內, 期待用戶在了解大概資訊後, 能主動在 附近與用戶有其他互動。活動將以列表呈現其類別與資訊, 另一頁面以 GPS 定位, 顯示其距 離。

\section{2 雛形設計訪談}

以初步手繪概念草稿，對於三位外向型學生進行訪談，分別來自電機系、傳播所以及外 文系。整理受訪者知訪談內容，共有三個問題:第一，人與活動皆以 GPS 位置與表列方式呈 現，兩者呈現資訊略有不同，容易找不到資訊，使用方式不同，希望可以有統一、清楚的呈 現方式。第二，GPS 位置結合AR 技術呈現附近用戶的資料，採左右移動來搜尋附近用戶， 很像羅盤的操作方式, 可以以此為概念進行深入的設計。第三, 推薦話題的功能, 可以考慮 不要, 只想要知道他的興趣、專業就可以。且活動部分很有趣, 可以對於此部分增加功能。

\section{3 修改設計}

根據訪談內容, 再做更深入研究, 認為 app 頁面以羅盤概念設計較佳, 刪除列表的形式, 皆 以羅盤為主畫面, 既能以內 圈與外圈表示距離, 也可以表示興趣與專業的相關性, 越內圈 越 接近自己表示與使用者越相關, 讓使用者一目了然, 可以依自己的喜好做選擇。將話題功能 刪除, 只呈現興趣與專業於個人頁面, 活動部分另外移出, 做成 GPS 定位搜尋, 也會依相 關 性與距離呈現於羅盤頁面上。

\section{4 任務設計與使用者測試}

本研究使用者測試, 共設計兩個任務, 第一個任務為: 使用APP在公車站附近尋找興趣相 同的異性, 進行對話。第二個任務為: 在附近尋找有興趣的活動, 參加並設置時間提醒。主 要想了解使用者如何尋找對象與活動、如何開始對話, 且在過程中操作是否遇到困難。受測 者共五位, 皆為使用手機APP與交友軟體之專家使用者。平均完成任務一的時間為 19 秒, 最快為 5 秒, 最慢為 40 秒; 任務二完成時間 17.6 秒, 最快為 20 秒, 最慢為 24 秒。

\section{6. 結論}

\section{1 使用者測試結論與修改意見}

使用者測試結果，以使用性目的分析整理如下：學習性方面，錯誤出現在兩個地方，第 一，是使用者會習慣上下滑動頁面，想要看更多訊息，且頁面也沒有告知已經到此頁面最底。 第二, 是看完個人頁面後, 不知道要怎麼到活動搜尋頁面, 按鈕只有字體, 沒有外框, 不易 辨識是否為按鈕，也不知道可以用滑動來切換頁面。在這些錯誤的時後，也沒有適當的提醒。 效率性部分, 雛型的按鈕偶爾會延遲幾秒反應, 讓受測者以為按鈕無法使用。有三位使用者 會重複按, 另外兩位, 一位是會按其他按鈕, 一位是會滑動頁面。錯誤回覆與預防部分, 目 前雛形並沒有錯誤的提醒，也沒有錯誤後的步驟提醒。記憶性部分，第二次任務平均時間比 第一次快 1.4 秒, 第二次任務之錯誤也從平均 2.2 次減少到 1.2 次, 因兩次任務有相同操 作模式，使用者有將第一次任務所學，應用於第二次的任務中。滿足感部分，測試後，對於 五位受測者進行訪談，訪談根據 The Human-computer Interaction Handbook: Fundamentals, 
Evolving Technologies, and Emerging Applications ，一書中的Online communities 章節提出的 線上社群使用者測試問題進行訪談。

五位受測者皆表示在學校中，等公車或空閒時間會想用此 app。而針對活動部分，有分 成三種意見: 第一, 不管公開或私人舉辦的活動, 皆會參加; 第二, 只參加公開活動, 認為 私人活動有安全性的問題, 不知道是不是可信任; 第三, 只參加私人活動, 認為私下約打球、 私下約逛街這種, 是可以接受的。三種回答皆顯示, 受測者願意參與活動, 不管公開與私人, 都有各自的喜好, 但此 app 還需要針對安全性部分發展功能, 如: 審核機制或回饋機制。而 對於再次使用此app 之意願, 有兩位受測者表示, 要看參加完活動的經驗是否愉快; 也有兩 位表示, app 僅提供訊息, 不會在意活動如何, 會自己挑選並再次參加其他更新的活動。另 一位, 則表示可能比較想要用來認識不同領域的人, 活動部分應該會比較少有機會參與。

\section{References}

[1] Sears, Andrew, and Julie A. Jacko, eds. The human-computer interaction handbook: fundamentals, evolving technologies and emerging applications. CRC press, 2007.

[2] S. K. Goyal, A joint economic-lot-size model for purchaser and vendor: A comment, Decision Sciences, vol.19, pp. 236-241, 1988.

[3] Susan Farrell. "UX Research Cheat Sheet. Nielson Norman Group, 2017. Web. 15 July 2019. https://www.nngroup.com/articles/ux-research-cheat-sheet/

[4] OLDENBURG, Ray. The Great Good Place (Third Places). New York: Marlowe\&Company, 1998. 